\title{
Developing a College Library Staff
}

Louise Richardson is librarian of the State College for Women Library, Tallahassee, Fla.

$\mathrm{T}_{\mathrm{i}}$

HIS Discussion of developing a college library staff for both the functional and the subject organization of the library is limited to the college library, because its work differs from that of a university in being concerned chiefly with undergraduates and with one educational unit. The staff as here considered includes the librarian and professional assistants, but not the student or clerical staff. Functional organization of the library includes the plan of operation and service, such as work in acquisitions, cataloging, lending, and reference. Subject organization covers background and knowledge in subject fields of the professionally trained staff.

Developing the library staff begins with the librarian, for the library will seldom be better than its librarian. I do not agree unqualifiedly with the president of Brown University when he says, "The least important qualification of the librarian is his training." ${ }^{\prime}$ The very nature of his position and the function of the college library make the training of the librarian important. He should be a scholar and have the attitude of a first-rate teacher, but he must go even further-he must know the functional organization of material and the administration of personnel.

\footnotetext{
1 Wriston, Henry M. "College and University Libraries." In Danton, Emily M., ed. Library of Tomorrow. A.L.A., 1939. p. 147.
}

Assuming a good general education, the librarian should be trained in technique (not necessarily routine) and this training should be followed by discipline in service, in order to know applied technique.

The functional processes of a wellorganized library are inseparably interwoven, and each process in its relation to all others needs clear understanding on the part of the administrative head. In short, nothing else entirely takes the place of training and experience. For this reason, it seems to me, the college librarian should not be one who steps from library school, undergraduate or graduate, into this administrative position. The trained person who knows first hand the toils and problems of acquisition, circulation, reference, and even cataloging work, is better able to organize the library; better able to develop a normal or superior staff; and better able to meet with assurance and decision the administrative problems to be discussed with the administrative head of the college. Such a librarian inspires the confidence of the staff and commands its respect, without which the service of the library suffers. The librarian needs "a command of library procedures on which to build professional performance."

There seems to be a tendency nowadays to waive much of this in filling certain positions. More men, for instance, are being appointed to executive positions-an undesirable policy unless the man is ap- 
pointed on his qualifications. Sex should not be the deciding factor. Requirements of training, experience, personality, executive ability, and scholarship are as necessary for the one as for the other.

I agree readily that technical training plus experience is not a substitute for knowledge in subject fields. Knowledge of library science, scholarly knowledge in other fields, and thorough understanding of functional relationships are inseparable in effective college library service. But, other things being equal, the person with executive ability who has been an assistant in one or more of the functional divisions of a library is better qualified, it seems to me, to become librarian than the person without practical experience in applied techniques. These technical skills, along with a thorough knowledge of the role of the library in an educational institution, of the educational objectives and curriculum of the college, and of the needs of both students and faculty, are the foundation upon which we set to work to make the library function as an auxiliary teaching instrument.

\section{Organizing the Staff and Promoting Morale}

In developing the staff for the functional organization of the library the following suggestions may serve as a starting point from which to work:

I. The greatest care possible is not too much in the selection of staff personnel. This may be done in one, or both, of two ways: (a) by thorough investigation of each applicant academically, professionally, and experientially; (b) by conference with the applicant.

We expect the professional staff to possess technical and bibliographical knowledge essential to the processes of administration for which they are employed, but in many cases too little is done in getting all possible information as to personality, adaptability, ability to work with others, and interest in people as well as in books.

2. All plans for the library and the real problems of the library should be laid, first, before the department concerned and, second, before the professional staff as a group.

This practice is especially desirable in any new plan or in a proposed change of existing policy. It makes for unity of purposes and for a balanced consideration of all facts from which a decision is ultimately to be made.

3. Staff discussion should be encourageddiscussion of procedures, of service, and of problems as they arise. Such discussion makes for constructive criticism and tends to prevent useless complaint and dissatisfaction. It also promotes enthusiastic cooperation, so essential in the work of the library.

4. Graduates of several library schools should be employed. In such a group several viewpoints are represented, from which progressive ideas are likely to develop. While differences may never be made to agree, the stimulation is vigorous and the result is apt to be healthy. "Consider divergent points of view and out of them develop a wise forward policy."2

5. Hard and fast departmental lines should be avoided. Stress cooperation, coordination, interdependence, and integration of departments. This is more easily said than done, but the librarian who has vision and who keeps clearly in mind the purpose of the whole library can foster this interrelationship of departments.

6. Interchange of schedule and occasional shifts in assignments, whenever possible, are helpful in giving each person a practical view of the other's work and a feeling of the whole. Such changes and shifts may be more practical for assistants than for heads of departments.

7. Time allowed in the schedule for some professional reading or study of the curriculum yields big returns, and is a policy which encourages "thinking on the spot."

${ }^{2}$ Tead, Ordway. Human Nature and Management. McGraw-Hill, 1929, p. 159. 
8. Responsibility, with corresponding authority, should be delegated to heads of departments; then each should be given a free hand in developing his division of the work. Making each assistant responsible for some particular share of work, however small, also helps in staff development. The librarian may observe the whole and keep in touch with all, but refrain from interference, except in cases of real need.

9. After responsibility has been delegated, give credit where credit is due for work well done. I know of no single thing which so encourages a staff to greater effort, to more enthusiastic interest, than does this simple, but to some librarians difficult, practice.

Io. The librarian sometimes needs to get into "the thick of the fray," not for critical purposes but to see situations as they really are and firsthand to ascertain difficulties, working conditions, and inadequacies in service. For this nothing else seems to be so satisfactory as an actual schedule for the librarian of a few hours each week in loan and reference departments. Time thus spent produces a pleasing, somewhat intangible, but potent effect on staff morale.

\section{Subject Organization}

Another phase of library development is that concerned with subject organization. For subject organization of the work of a college library, the professional staff should have varying backgrounds in subject knowledge. Many have backgrounds in English and history, but this is not enough. In selecting professional assistants the librarian should make an effort to select each assistant with a different subject.background: one trained in fine arts, one in language and literature, one in social sciences, one in biological sciences, one in physical sciences, or one with a combination of sciences. In this way personnel of staff may be strengthened for both the functional and subject needs of the library, and the smaller college li- braries which cannot afford a large reference staff can at least have some of the main subject fields covered by other members of the staff. These, then, would be available for consultation in matters concerning their various subject fields.

The necessity for familiarity with the literature of particular subjects needs no amplification for college librarians. In this respect they must meet the faculty on a scholarly level; they must be able to integrate library services, functions, and resources with the educational program of the college. For better service to students and faculty, for better and more thorough contact between people and books, for stimulation of student minds, and for lasting results in reading interests and habits, there is reason enough for having staff representatives in a variety of subject fields. At the same time we shall probably have to maintain to a considerable extent that encyclopedic interest and information to which we seem to commit ourselves when we become librarians.

By knowledge in a subject field I do not mean specialization in a narrow intellectual or scientific sense. To me this sort of specialization has no essential place in the subject organization of a college library. I personally do not believe that the Ph.D. degree is necessary for the college librarian unless such a degree is available along broader lines than is now obtainable. There is a regrettable tendency today to appoint as heads of departments, and as librarians, those who have Ph.D. degrees but no library training. As long as we librarians do such things in our own ranks, would it not be more becoming in us to say less than we have about some of the recent appointments to certain state and national positions? 


\section{Developing Subject Familiärity}

But suppose we already have our staff, a good one too, not chosen primarily for knowledge in subject fields, then what? Begin development where we are:

I. By assigning to each member of the professional staff, after conference as to interests, the study of basic bibliography in the field decided upon.

2. By having the person read widely authorities in the field. Here the faculty will be glad to lend a helping hand.

3. By making a reading list in the field, such a list to be primarily for students.

4. By planning a program for the systematic building of the book collection in the field, with the assistance of faculty specialists.

5. By giving the staff members opportunity to take a course or courses in the subject selected. This practice may be regarded as among the most important for keeping the staff intellectually competent. ${ }^{3}$

6. By the librarian's guiding, encouraging, and participating in such a program as above given for development in the subject fields.

Thus far I have not mentioned financial

${ }^{3}$ Gapp, Kenneth S. "The Librarian's Task in Improving Personnel." College and Research Libraries I:1 35, Mar, 1940. encouragement as a part of the program for development of the staff, but no phase of it is more important. Psychic remuneration (enjoyment of work) is not enough. Salaries are a tangible source of inspiration, for both greater effort and further study. Here, I think, the librarian is obligated to work unremittingly until a salary level comparable, at least, to that of the teaching staff is reached for staff members with equivalent training and experience. Such a scale of salaries should enable the librarian to secure the best possible staff as to training, experience, and knowledge of subject literature. No salary scale short of this is adequate for the library which is actively participating in the college program.

Emphasis upon scholarship and development in subject fields should not lead to subordination of technical and administrative ability. ${ }^{4}$ All phases of staff development resolve themselves into a whole, each complementing the other. Upon the librarian rests the responsibility and the duty of effecting such development.

\footnotetext{
4 Ibid.
} 